\title{
The p38 MAPK and NF-кB Pathways are Involved in Cyclic Compressive Force-induced IL-6 Secretion in MLO-Y4 Cells
}

\author{
Xiwen Chen ${ }^{1} \&{ }^{2}$, Wenchuan Chen ${ }^{1 *}$, Yun He$^{3}$, Yixin Zhang1, Chenfeng Chen ${ }^{1}$, Zhimin \\ Zhu', Hang Wang ${ }^{1}$ \\ ${ }^{1}$ Sichuan University West China College of Stomatology, State Key Laboratory of Oral Diseases, National Clinical \\ Research Center for Oral Diseases, West China Hospital of Stomatology, Chengdu, China; ${ }^{2}$ Department of \\ Stomatology, The Third People's Hospital of Southwest Jiaotong University; ${ }^{3}$ School of Medicine and Nursing, \\ Chengdu University Chengdu, Sichuan, China.
}

\begin{abstract}
We previously revealed the involvement of extracellular regulated protein kinases 1/2 (ERK1/2) in interleukin-6 (IL6) secretion induced by cyclic compressive force (CCF) in MLO-Y4 cells. In this study, we investigated the contributions of the p38 mitogen-activated protein kinase (MAPK) and nuclear factor- $\kappa B$ (NF- $\kappa B$ ) pathways to IL-6 secretion by stimulating MLO-Y4 cells with CCF. At 80\% confluence, different magnitudes (1000 $\mu$ strain, 2000 ustrain and 4000 ustrain), frequencies $(0.5 \mathrm{~Hz}, 1.0 \mathrm{~Hz}$ and $2.0 \mathrm{~Hz})$ and durations $(10 \mathrm{~min}, 30 \mathrm{~min}, 1 \mathrm{~h}, 3 \mathrm{~h} \mathrm{and} 6 \mathrm{~h}$ ) of CCF were loaded onto cells using a four-point bending system. Flow Cytometry (FCM) analysis was used to analyze cell mortality rates after CCF loading. 338 and $p 65$ phosphorylation as well as I $\mathrm{C} \alpha$ degradation in MLO$Y 4$ cells were detected by Western blotting (WB). Changes in IL-6 secretion after inhibitor treatment were assessed by enzyme-linked immunosorbent assays (ELISAs). Cellular viability was over 90 percent after CCF. p38 and p65 phosphorylation increased under all conditions, whereas $I \kappa B \alpha$ protein levels decreased. However, phosphorylation and degradation were not completely dependent on the loading magnitude, frequency or duration. Furthermore, p38 inhibition using the specific inhibitor SB203580 reduced both p38 phosphorylation and IL-6 secretion. Similarly, $N F-\kappa B$ inhibition using BAY 11-7082 decreased p65 phosphorylation and IL-6 secretion but increased the concentration of I $\mathrm{K} B \alpha$. These findings reveal significant roles for the $p 38$ and $N F-\kappa B$ signaling pathways in IL-6 secretion induced by CCF in MLO-Y4 cells.
\end{abstract}

Keywords: interleukin-6; cyclic compressive force; p38 mitogen-activated protein kinases; nuclear factor- $\mathrm{B}$; osteocyte

\footnotetext{
${ }^{*}$ Author for correspondence: hxkqcwc@scu.edu.cn
} 


\section{INTRODUCTION}

Bone mass in a healthy human body is maintained by a dynamic balance between osteoclastic bone resorption and osteoblastic bone remodeling ${ }^{1}$, which are regulated by a variety of mechanical stressors. The biological reaction of bone to mechanical stimulation consists of an intracellular process that is conducted and regulated by different molecules, cytokines and cellular pathways. Osteocytes, a cell type that is plentiful in bone, are essential transducers for biological signal conduction. During cell-to-cell communication, bone cells perceive stresses or strains resulting from mechanical pressure and translate these mechanical signals into biochemical signals ${ }^{2}$. Interleukin (IL)-6 is a keystone cytokine in health and disease and has a broad effect on cells. However, the signaling cassette and transfer mechanism that control the activity of IL-6 is complicated ${ }^{3}$. Wu ${ }^{4}$ found that IL-6 enhances osteocyte-mediated osteoclastogenesis by promoting JAK2 and RANKL activity. Kazuhiro's study ${ }^{5}$ demonstrated that a combination of TNF and IL-6 can induce bone-resorptive activity in osteoclast-like cells. Indeed, IL-6 plays a significant role as a biochemical regulator during osteoclastogenesis and bone resorption and regeneration ${ }^{6,7}$. In addition, pressure stress typically leads to both physiological and pathological bone tissue resorption. Previously, we performed microarray analysis and revealed the induction of IL-6 mRNA expression in MLO-Y4 cells in response to cyclic compressive force (CCF) ${ }^{8}$. In another study, we demonstrated the involvement of ERK1/2 in this induction 9 . However, whether additional cellular pathways are involved in this process remains unknown.

According to our microarray analysis, the p38 mitogen-activated protein kinase (MAPK) pathway plays a role in bone tissue absorption ${ }^{8}$. The p38 pathway is a stress response signaling pathway that is activated by intracellular and extracellular stresses, including environmental changes and exposure to inflammatory cytokines or other biosynthetic stresses ${ }^{10}$. The p38 pathway is thus involved in variety of biological responses as well as molecular regulation ${ }^{11,12}$. We hypothesized a role for p38 in IL-6 secretion by MLO-Y4 cells stimulated by CCF.

The NF- $\mathrm{KB}$ pathway is another crucial cellular signaling pathway involved in bone metabolism ${ }^{13,14}$. Five proteins comprise the NF- $\kappa B$ family: p50, RelA (p65), RelB, p52, and c-Rel. All exist as homodimers or heterodimers. Additionally, NF- $\mathrm{BB}$ is a nuclear transcription factor that is activated rapidly by different stimuli, such as inflammatory cytokines, including IL- 1 and TNF- $\alpha$; a number of growth factors; and mechanical stress inducers ${ }^{15,16}$. Furthermore, both p38 and NF- $\mathrm{kB}$ exert synergistic regulatory and biological effects on bone metabolism ${ }^{11,17-19}$.

The purpose of this study was to therefore investigate whether p38 and NF- $\mathrm{kB}$ are activated during CCF-stimulated IL-6 secretion in MLO-Y4 cells. In addition, we sought to determine how the mechanical force parameters of CCF affect p38 phosphorylation, NF- $\kappa B$ activation and IL-6 secretion.

\section{MATERIAL AND METHODS}

\section{Cell culture}

Cells were cultured in $\alpha$-MEM (Gibco, NY, USA) supplemented with $10 \%$ fetal bovine serum (HyClone Lab, China), $100 \mathrm{mg} / \mathrm{mL}$ streptomycin (Sigma, St. Louis, MO, USA), and $100 \mathrm{U} / \mathrm{mL}$ penicillin (Sigma, St. Louis, MO, USA) and incubated in $5 \% \mathrm{CO}_{2}$ and $95 \%$ air at $37^{\circ} \mathrm{C}$. The medium was replaced every other day. 


\section{CCF stimulation}

Adherent cells were digested once they reached 70 to $80 \%$ confluency, and $5 \times 10^{5}$ cells were seeded onto collagen-coated bending plates. The rectangular plates were 4 $\mathrm{cm}$ by $8 \mathrm{~cm}$ in length and $1.5 \mathrm{~mm}$ in thickness. After incubation for $12 \mathrm{~h}$, the cells were then subjected to CCF. The compressive force was generated using a four-point bending system (Figure. 1$)^{20}$.

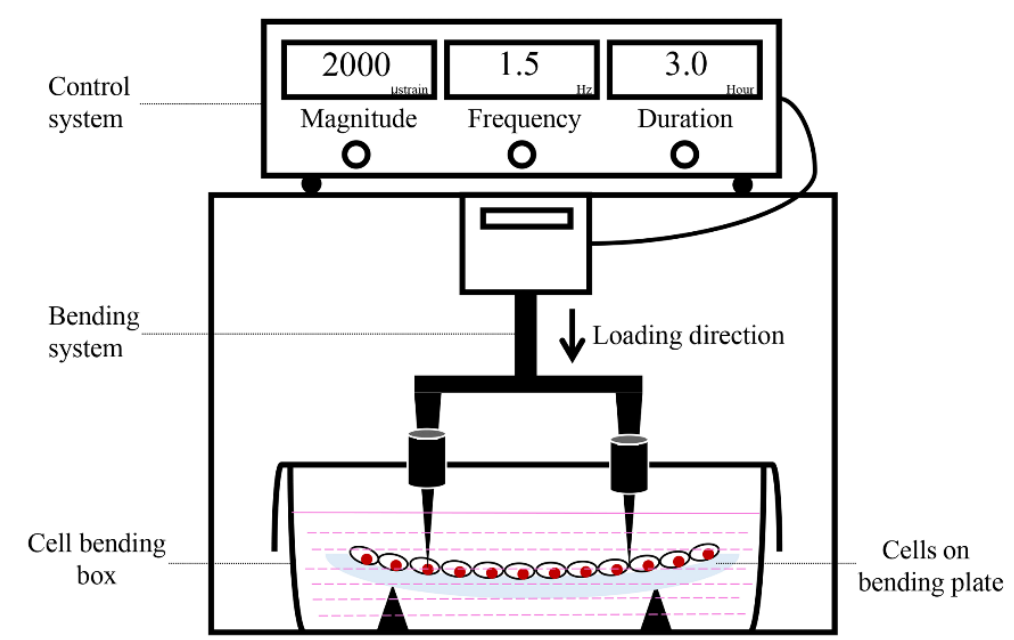

Figure. 1: Cyclic compressive force loading schematic. A four-point bending system consists of a control system and a bending system. Different magnitudes, frequencies and durations are set by the control system, while cells are stimulated by the bending system.

The first group of cells was subjected to $\mathrm{CCF}$ at $2 \mathrm{~Hz}$ for $1 \mathrm{~h}$ with diverse magnitudes (1000 $\mu$ strain, $2000 \mu$ strain, and $4000 \mu$ strain). The second group of cells was loaded at $2000 \mu$ strain for $1 \mathrm{~h}$ with various frequencies $(0.5 \mathrm{~Hz}, 1 \mathrm{~Hz}$, and $2 \mathrm{~Hz})$. The third group of cells was stressed at $2 \mathrm{~Hz}$ and $2000 \mu$ strain for $10 \mathrm{~min}, 30 \mathrm{~min}, 1 \mathrm{~h}, 3 \mathrm{~h}$, and 6 $\mathrm{h}$. The control group of cells was cultured under the same conditions without any mechanical stimulation. These controls were defined as time zero for all experiments.

\section{Flow cytometry analysis}

Flow cytometry (FCM) analysis was used to determine the cellular viability of MLOY4 after CCF loading. After loading, supernatant was collected in $15 \mathrm{ml}$ centrifuge tubes (Corning, Corning, New York, USA). Cells were washed with cold phosphatebuffered saline (PBS) and digested with 0.25\% Trypsin Solution without EDTA (T1350, Beijing Solarbio Science \& Technology Co., Ltd, Beijing, China). Cells were then collected into the same centrifuge tube and centrifuged at $2000 \mathrm{rpm}$ for $5 \mathrm{~min}$. Cells were then washed twice with cold PBS, and centrifuged at $2000 \mathrm{rpm}$ for $5 \mathrm{~min}$ after each wash. Cells were suspended with $500 \mu \mathrm{l}$ of binding buffer (KGA107, Keygen biotech, Jiangsu, China) and transferred into flow tubes (352054, BD Falcon, New York, USA); $5 \mu$ l of annexin V-FITC (KGA107, Keygen biotech, Jiangsu, China) and $5 \mu \mathrm{l}$ of propidium iodide (PI, KGA107, Keygen biotech, Jiangsu, China) were then added in turn according to the manufacturer's instructions. The samples were then incubated in a dark chamber at room temperature for $15 \mathrm{~min}$, and FCM analysis was performed within 1 hour. The excitation wavelength was $488 \mathrm{~nm}$, and the emission wavelength was $530 \mathrm{~nm}$. Green fluorescence from annexin V-FITC was detected in the FL1 channel. Red fluorescence from PI was detected in the FL3 channel. The test 
was automatically completed when 20000 cells had been counted or the test had proceeded for 120 seconds.

\section{Western blotting}

After the cells were loaded, they were washed twice with cold PBS and then harvested on ice in lysis buffer. After centrifugation, the supernatants were used for Western blotting analysis. Equal amounts of different proteins were transferred onto PVDF membranes. All membranes were incubated with different primary antibodies against phospho-p38, IкB $\alpha, \beta$-actin and phospho-p65. After an overnight incubation at $4{ }^{\circ} \mathrm{C}$, all PVDF membranes were washed twice in TBST and TBS for $10 \mathrm{~min}$. Then, the membranes were then incubated with a secondary antibody for $1 \mathrm{~h}$ at $37^{\circ} \mathrm{C}$. An ECL Western Blot Detection Kit was used to collect images of visible immunoreactive bands. The band intensity ratios for p-p38, p38 (p-p38/p38), NF- $\kappa B$ and $\beta$-actin

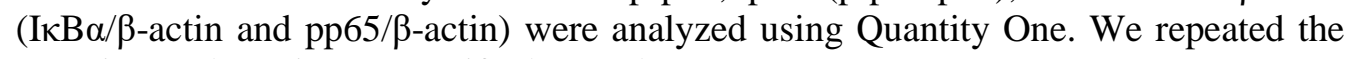
experiment three times to verify the results.

\section{Inhibition study to investigate cellular signaling pathways}

The roles of the p38 and NF- $\mathrm{kB}$ pathways in the response to CCF in MLO-Y4 cells were assessed by blocking these pathways with a p38-specific inhibitor (SB203580, Beyotime Institute of Biotechnology, China) and an NF-kB-specific inhibitor (BAY 11-7082, Beyotime Institute of Biotechnology, China). The cells were pretreated for 1 $\mathrm{h}$ in culture medium with SB203580 $(10 \mu \mathrm{M})$ or BAY 11-7082 $(100 \mu \mathrm{M})$. Then, cells were stressed in the same medium used for the other groups.

Changes in IL-6 secretion were assessed by performing an enzyme-linked immunosorbent assay (ELISA). After inhibitor treatment and CCF stimulation, media were collected, centrifuged and stored at $-70^{\circ} \mathrm{C}$. All samples were analyzed by ELISA (Senxiong, Shanghai, China) according to the manufacturer's protocol. Each sample was tested twice to verify the results.

\section{Statistical analysis}

Statistical analyses were performed using one-way ANOVA (SPSS) followed by the post hoc SNK test for multiple comparisons at $\alpha=0.05$.

\section{RESULTS}

\section{The effects of CCF on cellular viability}

According to the results of FCM analysis (Figure. 2), the cell viabilities following exposure to different magnitudes, frequencies, and durations of CCF were all over $95 \%$. 

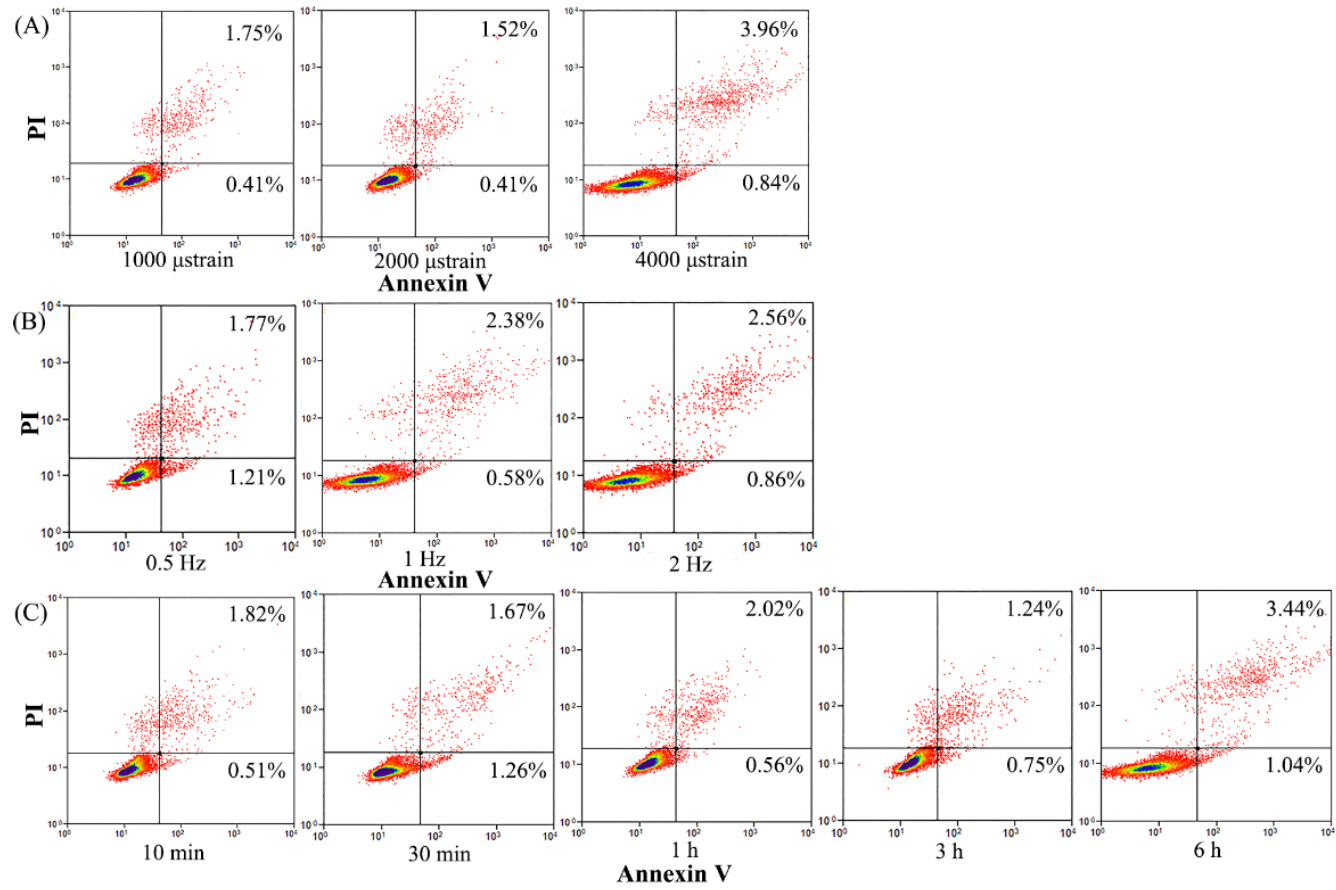

Figure. 2: The effects of CCF on cellular viability as analyzed by flow cytometry. (A) The effect of different loading magnitudes on cellular viability: cells were loaded at $2 \mathrm{~Hz}$ under various magnitudes (1000, 2000 and 4000 $\mu$ strain) of force for $1 \mathrm{~h}$. (B) The effects of different loading frequencies on cellular viability: cells were stressed at $2000 \mu$ strain under different frequencies $(0.5,1$ and $2 \mathrm{~Hz}$ ) for $1 \mathrm{~h}$. (C) The effects of different loading duration on cellular viability: cells were subjected to $\mathrm{CCF}$ at $2 \mathrm{~Hz}$ and $2000 \mu$ strain for $10 \mathrm{~min}, 30 \mathrm{~min}, 1 \mathrm{~h}, 3 \mathrm{~h}$ and $6 \mathrm{~h}$, respectively. Red clusters in the upper right quadrant represent apoptotic cells after loading. The apoptosis rate of each group is indicated in the same quadrant.

\section{The effects of CCF on p38 phosphorylation}

When cells were stimulated at $2 \mathrm{~Hz}$ for $1 \mathrm{~h}$, all three tested loading magnitudes increased p38 phosphorylation levels (Figure. 3 A, greater than control, p<0.05). Comparisons between any two loading groups revealed significant differences between them $(\mathrm{p}<0.05)$. Increased $\mathrm{p} 38$ phosphorylation also occurred with different frequencies (Figure. $3 \mathrm{~B}$ ). Specifically, cells stimulated at $0.5 \mathrm{~Hz}, 1 \mathrm{~Hz}$ and $2 \mathrm{~Hz}$ exhibited increased p38 phosphorylation $(\mathrm{p}<0.05)$ compared with the control group, and significant differences between $0.5 \mathrm{~Hz}$ and $2 \mathrm{~Hz}$ were noted $(\mathrm{p}<0.05)$. As shown in Figure. 3 C, p38 was significantly activated when the frequency was maintained at $2 \mathrm{~Hz}$ and the loading magnitude at $2000 \mu$ strain, and activity increased rapidly at 10 min, after which it increased gradually until it peaked after $3 \mathrm{~h}$, then decreased at $6 \mathrm{~h}$. 


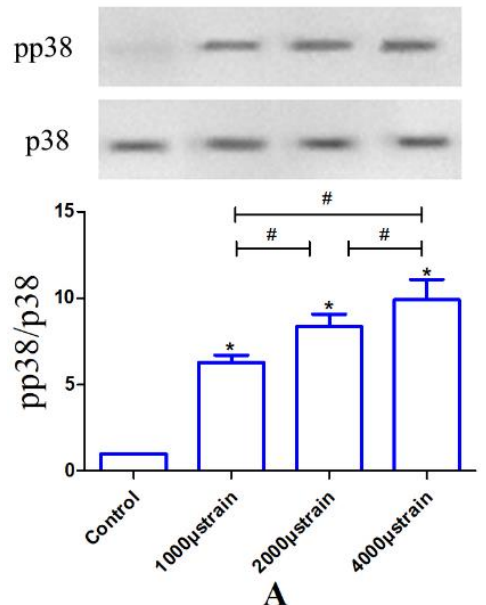

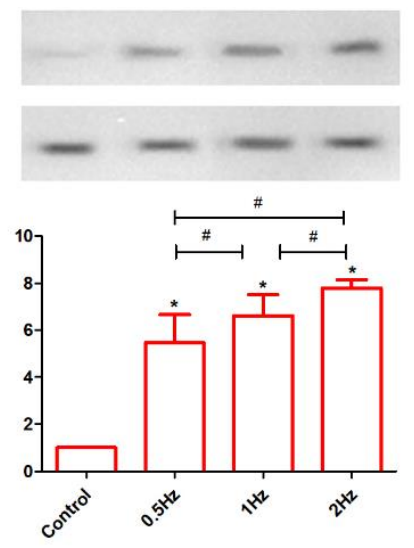

B

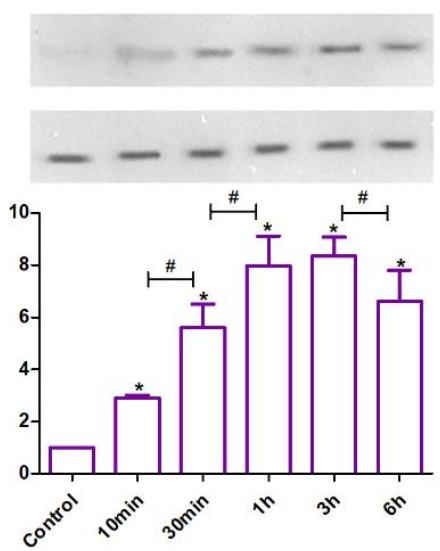

C

Figure. 3: The effects of CCF on p38 phosphorylation. (A) The effects of loading magnitude: cells were loaded at 2 $\mathrm{Hz}$ under various magnitudes (1000, 2000 and $4000 \mu$ strain) for $1 \mathrm{~h}$. (B) The effects of loading frequency: cells were stressed at $2000 \mu$ strain under different frequencies $(0.5,1$ and $2 \mathrm{~Hz})$ for $1 \mathrm{~h}$. (C) The effects of loading duration: cells were subjected to CCF at $2 \mathrm{~Hz}$ and $2000 \mu$ strain for $10 \mathrm{~min}, 30 \mathrm{~min}, 1 \mathrm{~h}, 3 \mathrm{~h}$ and $6 \mathrm{~h}$. ${ }^{*} \mathrm{P}<0.05$ vs. control, $\# \mathrm{P}<0.05$.

\section{The effects of CCF on IKB $\alpha$ degradation}

$\mathrm{I} \kappa \mathrm{B} \alpha$ protein degradation was measured by Western blotting, and the luminance value

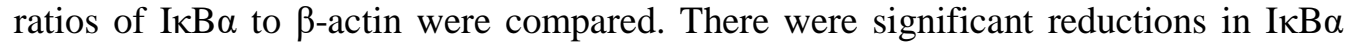
after different CCF loading magnitudes were applied compared with the control $(\mathrm{p}<0.05$, Figure. 4 A). Specifically, there was a significant difference between 1000 $\mu$ strain and $2000 \mu$ strain as well as $1000 \mu$ strain and $4000 \mu$ strain $(\mathrm{p}<0.05)$ but not between $2000 \mu$ strain and $4000 \mu$ strain. Similar reductions in I $\mathrm{B} \alpha$ occurred at different frequencies (Figure. 4 B) with significant differences between loading groups and the control $(p<0.05)$. Specifically, there was a statistically significant difference between $0.5 \mathrm{~Hz}$ and $1 \mathrm{~Hz}(\mathrm{p}<0.05)$, but there was no difference between $1 \mathrm{~Hz}$ and 2 $\mathrm{Hz}$. A rapid reduction in I $\mathrm{KB} \alpha$ occurred after 10 min of loading ( $<<0.05$, Figure. $4 \mathrm{C}$ ). Additionally, statistical differences were noted between $10 \mathrm{~min}$ and $30 \mathrm{~min}(\mathrm{p}<0.05)$ as well as $1 \mathrm{~h}$ and $3 \mathrm{~h}(\mathrm{p}<0.05)$. No differences were noted between $30 \mathrm{~min}$ and $1 \mathrm{~h}$ as well as $3 \mathrm{~h}$ and $6 \mathrm{~h}$.
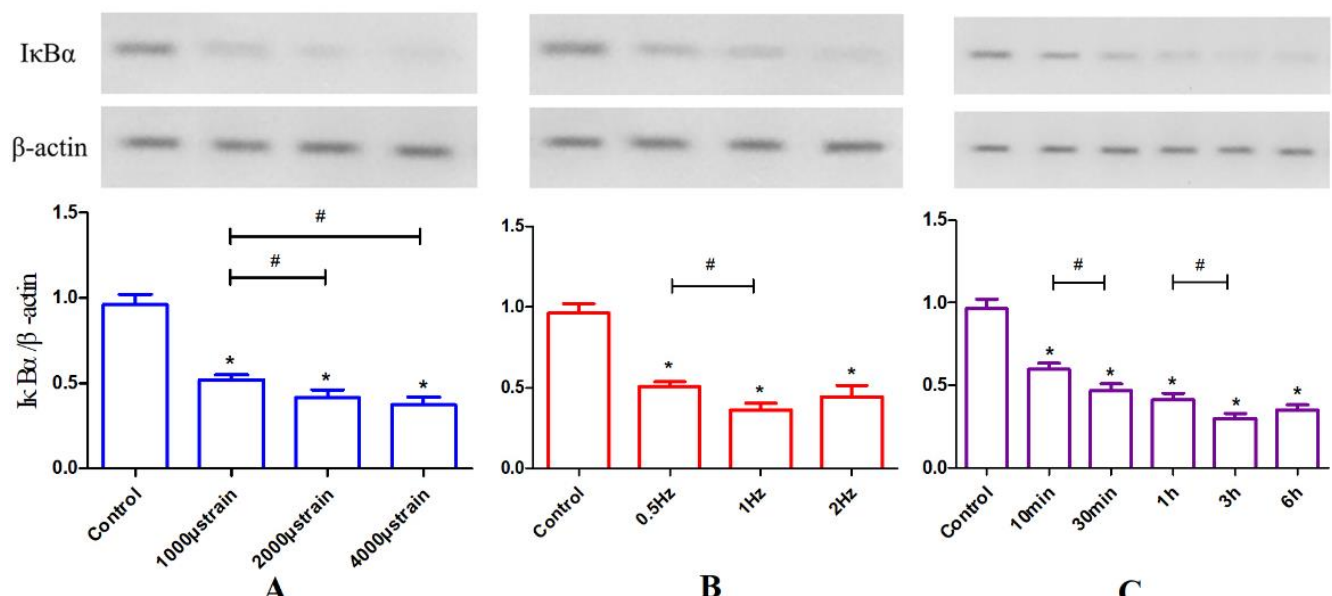

Figure. 4: The effects of CCF on I $\mathrm{KB} \alpha$ levels. (A) The effects of different magnitudes $(1000,2000$ and 4000

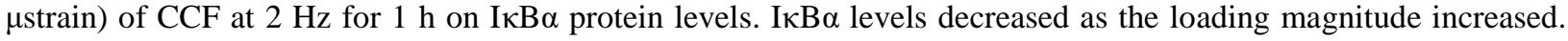
(B) The effects of loading frequency: cells were stressed at $2000 \mu$ strain at different frequencies $(0.5 \mathrm{~Hz}, 1 \mathrm{~Hz}$ and 2 $\mathrm{Hz}$ ) for $1 \mathrm{~h}$. I $\mathrm{KB} \alpha$ levels decreased as the loading frequency increased and reached its lowest point at $1 \mathrm{~Hz}$. (C) The 
effects of loading duration: I $\mathrm{B} \mathrm{B} \alpha$ levels decreased as the CCF duration increased and reached its lowest point at $3 \mathrm{~h}$. $* \mathrm{P}<0.05$ vs. control, \# $\mathrm{P}<0.05$.

\section{The effects of CCF on phospho-p65 protein levels in MLO-Y4 cells}

To examine whether I $\mathrm{KB} \alpha$ degradation caused the nuclear translocation of NF- $\kappa \mathrm{B}$, Western blotting was performed to detect the phospho-p65 (pp65) subunit (Figure. 5). Different magnitudes of CCF all significantly increased pp65 levels compared with those of the control $(\mathrm{p}<0.05$, Figure. $5 \mathrm{~A})$, although no statistical differences were noted between $1000 \mu$ strain, $2000 \mu$ strain and $4000 \mu$ strain. Significant differences were also observed between the loading groups and the control at different CCF frequencies (Figure. $5 \mathrm{~B}, \mathrm{p}<0.05$ ). The highest pp65 levels were observed in the $1 \mathrm{~Hz}$ group, while pp65 levels decreased at $2 \mathrm{~Hz}$. Statistical differences were noted between $0.5 \mathrm{~Hz}$ and $1 \mathrm{~Hz}(\mathrm{p}<0.05)$ as well as $1 \mathrm{~Hz}$ and $2 \mathrm{~Hz}(\mathrm{p}<0.05)$. pp65 levels gradually increased as the duration of CCF loading increased, but no significant differences were noted among the control, $10 \mathrm{~min}$ and $30 \mathrm{~min}$ groups (Figure. $5 \mathrm{C}$ ). However, pp65 levels at $1 \mathrm{~h}, 3 \mathrm{~h}$ and $6 \mathrm{~h}$ were significantly increased compared with the control, $10 \mathrm{~min}$ and $30 \mathrm{~min}$ groups $(\mathrm{p}<0.05)$. The $1 \mathrm{~h}, 3 \mathrm{~h}$ and $6 \mathrm{~h}$ groups did not differ significantly.
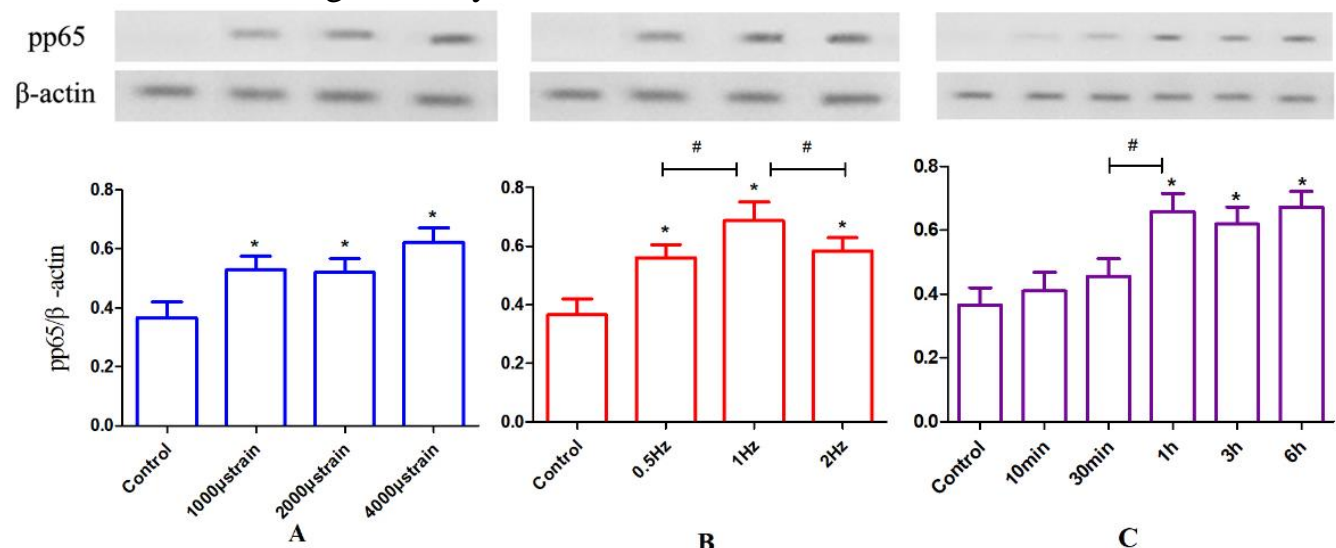

Figure. 5: The effects of CCF on p65 phosphorylation. (A) The effects of different CCF loading magnitudes at $2 \mathrm{~Hz}$ for 1 h. p65 phosphorylation levels increased after loading, but these effects were not related to magnitude. (B) The effects of different loading frequencies $(0.5 \mathrm{~Hz}, 1 \mathrm{~Hz}$ and $2 \mathrm{~Hz}):$ p65 phosphorylation levels increased and peaked at $1 \mathrm{~Hz}$. (C) The effects of loading duration: p65 phosphorylation also increased with increased duration and peaked at 1 h. $* \mathrm{P}<0.05$ vs. control, \#P<0.05.

\section{The effects of a p38 inhibitor on p38 phosphorylation and IL-6 secretion}

As shown in Figure. 6 A, cellular p38 activity was greatly diminished when MLO-Y4 cells were pretreated with the specific inhibitor SB203580 at $100 \mu \mathrm{M}$ for $1 \mathrm{~h}$ and then cultured with a loading magnitude of $2000 \mu$ strain at $2 \mathrm{~Hz}$ for $1 \mathrm{~h}$. Significant differences were observed compared with the group lacking the inhibitor $(p<0.01)$. However, p38 activity increased despite pretreatment with SB203580 compared with the control group, which was cultured without CCF $(\mathrm{p}<0.05)$. As shown in Figure. 6 B, IL-6 secretion decreased significantly under the same loading conditions when pretreated with the $\mathrm{p} 38$ inhibitor at $10 \mu \mathrm{M}$ for $1 \mathrm{~h}(\mathrm{p}<0.05)$; however, secretion was increased compared with the control. 

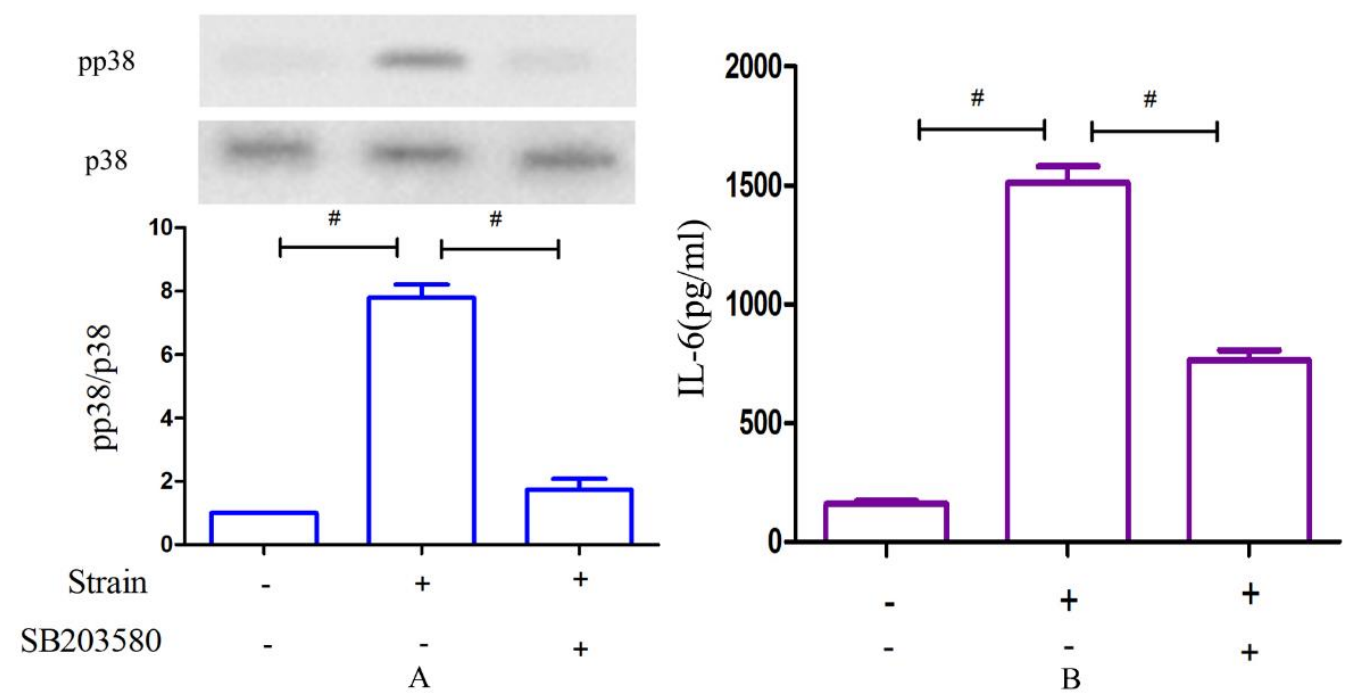

Figure. 6: The effects of a p38 inhibitor on p38 phosphorylation. (A) and IL-6 secretion (B). (A) Changes in p38 phosphorylation after CCF loading at $2000 \mu$ strain and $2 \mathrm{~Hz}$ for $1 \mathrm{~h}$ versus CCF loading after pretreatment with SB203580. (B) Corresponding changes in IL-6 secretion after CCF loading alone versus CCF loading following pretreatment with SB203580. \#P<0.05.

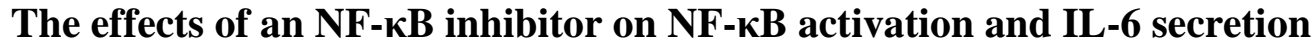

As shown in Figure. $7 \mathrm{~A}$, the I $\mathrm{KB} \alpha$ concentration was partially increased compared with the group stimulated only by CCF when MLO-Y4 cells were pretreated with the specific inhibitor BAY 11-7082 for $1 \mathrm{~h}$ and then cultured at $2000 \mu$ strain and $2 \mathrm{~Hz}$ for $1 \mathrm{~h}(\mathrm{p}<0.05)$. In addition, $\mathrm{p} 65$ phosphorylation was greatly decreased $(\mathrm{p}<0.05$, Figure. 7 B). Similar observations were made for IL-6 secretion: as shown in Figure. 5 C, IL-6 secretion significantly decreased under the same loading conditions after treatment with the inhibitor $(\mathrm{p}<0.05)$.

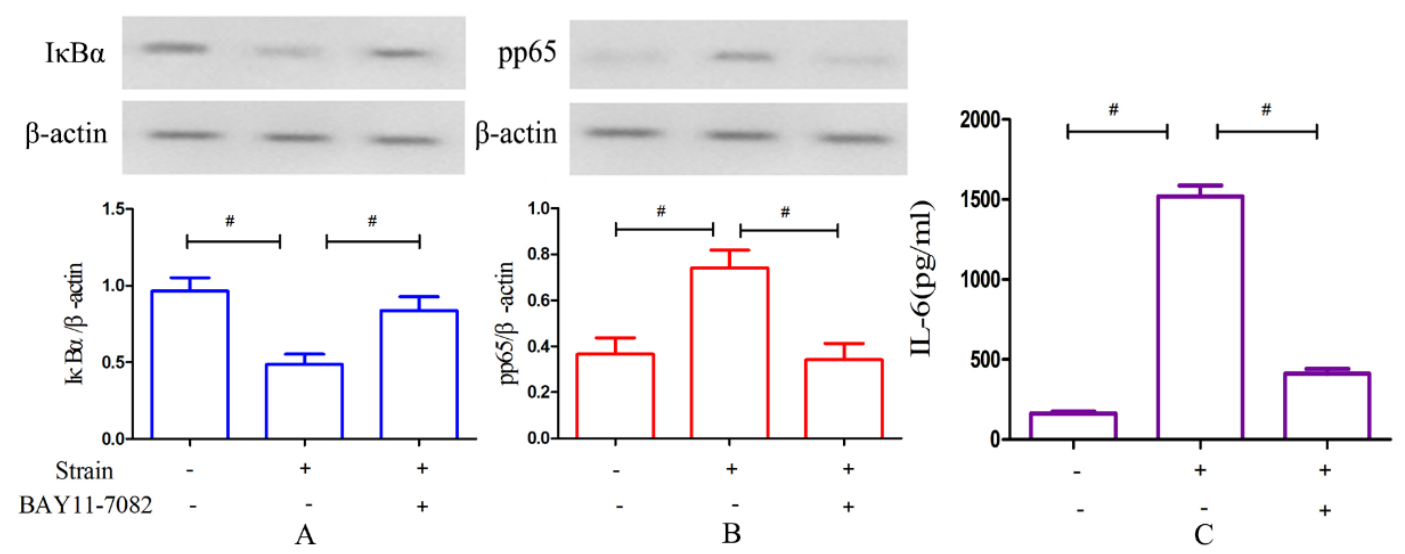

Figure. 7: The effects of an NF- $\kappa \mathrm{B}$ inhibitor on $\mathrm{I} \kappa \mathrm{B} \alpha$ levels. (A), p65 phosphorylation (B) and IL-6 secretion (C). (A) Changes in I $\mathrm{B} \alpha \alpha$ levels after CCF loading at $2000 \mu$ strain and $2 \mathrm{~Hz}$ for $1 \mathrm{~h}$ versus CCF loading after pretreatment with BAY 11-7082. (B) Changes in p65 phosphorylation after CCF loading only versus CCF loading after pretreatment with BAY 11-7082. (C) Changes in IL-6 secretion after CCF loading only versus CCF loading following pretreatment with the inhibitor. $\# \mathrm{P}<0.05$.

\section{DISCUSSION}

Various physical stimuli, such as low-intensity pulsed ultrasound ${ }^{21}$, low-power laser ${ }^{22}$, and CCF, have been applied to investigate cell proliferation and differentiation, 
secretion, apoptosis and relevant signaling pathways. Based on the results from our control group, detectable IL-6 secretion occurred in cells that did not receive stimulation. Bakker's study revealed that IL- 6 was produced by shear-loaded osteocytes and that IL- 6 affected bone mass by modulating osteocyte communication toward osteoblasts ${ }^{23}$. Additionally, different types of mechanical stresses augment IL6 secretion from osteocyte-like cells and other tissue-derived cells ${ }^{24-26}$. According to a previous study, osteoclast formation is significantly activated with the secretion of both IL-6 and soluble IL-6 receptor ${ }^{27}$.

Using bioinformatics and molecular biology techniques, we confirmed the involvement of MAPK in bone remolding induced by mechanical stimulation. ERK1/2 pathway involvement was previously observed ${ }^{8,9}$. The p38 MAPK pathway, which is another significant subgroup of the MAPK superfamily, was involved in the response to proliferation-inducing stimuli in an osteoblastic cell line ${ }^{11}$. In addition, according to Sinfield's study, the p38 $\alpha$ subtype facilitates IL-1-induced IL-6 secretion by human cardiac fibroblasts ${ }^{12}$. Another study revealed that in MC3T3 cells, BMP4stimulated OPG synthesis might be upregulated by resveratrol via amplification of p38 MAP kinase activity ${ }^{28}$.

In unstimulated cells, nuclear localization signaling by NF- $\kappa B$ is effectively inhibited

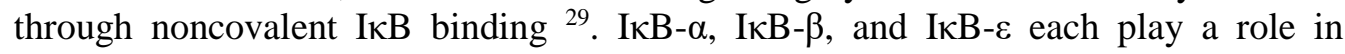
stimulus-induced degradation, which is the key step in NF- $\kappa B$ activation. Stimulatory signals induce the phosphorylation of I $\mathrm{KB}$ (particularly $\mathrm{I} \kappa \mathrm{B} \alpha$ ) by a ubiquitindependent protein kinase followed by ubiquitination at nearby lysine residues and proteolytic degradation.

Activated NF- $\mathrm{KB}$ rapidly translocates into the nucleus and regulates a group of NF$\kappa \mathrm{B}$-responsive effector genes ${ }^{29}$. According to previous studies, $\mathrm{p} 65$ phosphorylation may be necessary for the transcription of nuclear NF- $\kappa B^{30}$. Therefore, we investigated $\mathrm{I} \kappa \mathrm{B} \alpha$ and pp65 as key factors to indirectly assess NF- $\kappa \mathrm{B}$ activation.

Notably, MAPKs, including ERK and p38, are typically involved in bone metabolism in combination with NF- $\mathrm{KB}$ pathway activation ${ }^{11,19}$. Both pathways are associated with the inhibition of osteoclast formation by $\mathrm{K} 7$ in mouse bone marrow-derived macrophages ${ }^{19}$ as well as the therapeutic ultrasound-induced proliferation of MC3T3E1 cells ${ }^{11}$. Conversely, Wang's study suggests that amiloride-induced inhibition of p38 and NF- $\mathrm{KB}$ leads to downregulation of osteoclast-specific gene expression and bone resorption ${ }^{18}$. Thus, the MAPK, NF- $\mathrm{BB}$, and TRAF6 pathways are typically activated or involved in bone metabolism as well as intracellular conduction and regulation ${ }^{11,18,19,31}$.

In this study, rapid p38 phosphorylation and reduced $\mathrm{I \kappa B} \alpha$ protein and $\mathrm{p} 65$ phosphorylation levels were detected in the absence of any negative effects on cell viability when MLO-Y4 cells were stimulated with CCF. Thus, the p38 and NF-kB pathways were activated under our experimental conditions. Furthermore, the application of p38 and NF- $\mathrm{BB}$ inhibitors, specifically SB203580 and BAY 11-7082, respectively, provided additional evidence supporting the crucial role of these two pathways in cellular responses to CCF. IL-6 secretion decreased significantly after individual pretreatment with $10 \mu \mathrm{M}$ SB203580 and $100 \mu \mathrm{M}$ BAY 11-7082. Thus, CCF-induced p38 and NF- $\mathrm{kB}$ activations play significant roles in IL-6 secretion by MLO-Y4 cells.

In our study, p38 was rapidly activated under three different magnitudes of the CCF. Based on these findings, $1000 \mu$ strain of CCF is sufficient to trigger mechanical stimulation for bone remolding and bone resorption. In addition, p38 phosphorylation increased significantly with increasing magnitude, and the $4000-\mu$ strain group exhibited peak activation. I $\mathrm{B} \alpha$ levels were reduced whereas p65 phosphorylation increased after the application of different CCF magnitudes. The 2000- and 4000$\mu$ strain groups exhibited the lowest I $\mathrm{BB} \alpha$ levels, whereas pp65 levels were not 
associated with magnitude. Based on these findings, NF- $\mathrm{B}$ activity and changes in I $\kappa \mathrm{B} \alpha$ levels did not fully parallel pp65 levels. Thus, intracellular conduction at the molecular level was multidirectional and dynamic.

According to our experiments, dynamic loading induces bone formation in vivo, and the bone formation rate is modulated by the stimulus frequency ${ }^{32}$. p38 phosphorylation under different frequencies significantly differed compared with that in the control group, and the results were frequency-dependent. When the frequency was increased from 0.5 to 1 and $2 \mathrm{~Hz}, \mathrm{pp} 38$ levels were notably augmented. Thus, 0.5 $\mathrm{Hz}$ is sufficient to stimulate p38 activation, whereas $2 \mathrm{~Hz} \mathrm{CCF}$ did not achieve saturation to induce $\mathrm{p} 38$ activation in MLO-Y4 cells. When NF- $\kappa \mathrm{B}$ pathway activation was investigated, different frequencies of $\mathrm{CCF}$ resulted in decreased concentrations of $\mathrm{I} \kappa \mathrm{B} \alpha$, whereas p65 phosphorylation levels increased. I $\kappa \mathrm{B} \alpha$ levels were lowest and pp65 levels peaked in the $1-\mathrm{Hz}$ group. Thus, in response to CCF loading with a loading frequency of $1 \mathrm{~Hz}$ and $2000 \mu$ strain for $1 \mathrm{~h}, \mathrm{NF}-\kappa \mathrm{B}$ activation reached saturation.

Different impacts on bone tissue have been noted with differing loading durations. Rubin ${ }^{33}$ found that lower-magnitude loading resulted in the same anabolic effects achieved with higher-magnitude loading but only with a longer loading duration and regardless of the effects of osteogenesis saturation. In our study, p38 phosphorylation increased rapidly at $10 \mathrm{~min}$ and peaked at $3 \mathrm{~h}$. Then, pp38 levels decreased at $6 \mathrm{~h}$. Thus, p38 phosphorylation appears to undergo saturation; additionally, the p38 pathway is involved in IL-6 secretion. Activation of this pathway is a dynamic process. I $\mathrm{B} \alpha$ levels were reduced whereas pp65 levels increased with increased CCF duration. The I $\mathrm{\kappa B} \alpha$ concentration was lowest at $3 \mathrm{~h}$. However, pp65 levels rapidly increased at $1 \mathrm{~h}$, whereas no significant changes were noted at $3 \mathrm{~h}$ or $6 \mathrm{~h}$. These results

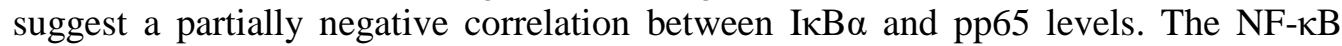
pathway is also dynamically involved in IL-6 secretion.

p38 and NF- $\mathrm{kB}$ likely play more significant roles than ERK1/2 in IL-6 secretion based on the results of our previous study. IL- 6 was reduced by only $35 \%$ when ERK $1 / 2$ was completely inhibited, but IL-6 levels were decreased by half when p38 was $80 \%$ suppressed. However, IL-6 secretion decreased by approximately $70 \%$ when I $\mathrm{KB} \alpha$ was activated by greater than 2 -fold and pp65 was 50\% suppressed. Based on these results, although the changes in I $\mathrm{KB} \alpha$ concentration and pp65 phosphorylation were not as drastic as the changes in pp38, their effects on IL-6 secretion were more significant. Clearly, the secretion process and its intracellular regulatory mechanism are complicated. A limitation of this study was its inability to reveal the relationships and interaction mechanisms among ERK1/2, p38 and NF-кB.

Understanding the mechanisms underlying physiological and pathological process is of significant interest for improving therapies and drug development ${ }^{34}$. IL-6 exhibits potent osteoclast activity, and ERK1/2 is involved in this process ${ }^{9,27,35}$. According to our study, p38 MAPK and NF- $\kappa$ B are also involved in IL-6 secretion stimulated by CCF in MLO-Y4 cells. We hypothesize that the induction of osteoclastogenesis and bone resorption via decreased IL-6 secretion through p38 and NF- $\kappa$ B pathway blockade holds value for the field of stomatology. For example, after implant surgery, pathway inhibition may facilitate satisfactory primary stability and rapid osseointegration. These pathways should be exploited to develop new therapies to cure periodontal diseases. Furthermore, additional studies investigating the molecular mechanisms underlying osteal production yield induced by mechanical stimulation would facilitate osteoporosis treatment and bone tissue engineering ${ }^{36}$. 


\section{CONCLUSIONS}

In our study, we demonstrated the involvement of the p38 MAPK and NF- $\mathrm{BB}$ pathways in CCF-stimulated IL-6 secretion by MLO-Y4 cells. p38 and p65 phosphorylation increased, whereas the I $\mathrm{I} \mathrm{B} \alpha$ concentration was reduced in all cases. However, these changes were not fully dependent on different CCF magnitudes, frequencies or durations. Furthermore, p38 and NF- $\kappa \mathrm{B}$ activation exert more potent effects on IL-6 secretion compared with ERK1/2. Consequently, the p38 MAPK and NF- $\mathrm{BB}$ pathways represent potentially important links between mechanical stress and bone resorption and remolding.

\section{REFERENCES}

1. Fujita K, Iwasaki M, Ochi H, Fukuda T, Ma C, Miyamoto T, et al. Vitamin E decreases bone mass by stimulating osteoclast fusion. Nat Med. 2012;18(4):589-594.

2. Bonewald LF. Mechanosensation and Transduction in Osteocytes. Bonekey Osteovision. 2006;3(10):7-15.

3. Hunter CA, Jones SA. IL-6 as a keystone cytokine in health and disease. Nat Immunol. 2015;16(5):448-457.

4. Wu Q, Zhou X, Huang D, Ji Y, Kang F. IL-6 Enhances Osteocyte-Mediated Osteoclastogenesis by Promoting JAK2 and RANKL Activity In Vitro. Cell Physiol Biochem. 2017;41(4):1360-1369.

5. Yokota K, Sato K, Miyazaki T, Kitaura H, Kayama H, Miyoshi F, et al. Combination of tumor necrosis factor alpha and interleukin-6 induces mouse osteoclast-like cells with bone resorption activity both in vitro and in vivo. Arthritis Rheumatol. 2014;66(1):121-129.

6. Huang RL, Chen G, Wang W, Herller T, Xie Y, Gu B, et al. Synergy between IL6 and soluble IL-6 receptor enhances bone morphogenetic protein-2/absorbable collagen sponge-induced bone regeneration via regulation of BMPRIA distribution and degradation. Biomaterials. 2015;67:308-322.

7. Cheung WY, Simmons CA, You L. Osteocyte apoptosis regulates osteoclast precursor adhesion via osteocytic IL-6 secretion and endothelial ICAM-1 expression. Bone. 2012;50(1):104-110.

8. Chen W, Qing H, He Y, Wang J, Zhu Z, Wang H. Gene expression patterns of osteocyte-like MLO-Y4 cells in response to cyclic compressive force stimulation. Cell Biol Int. 2010;34(5):425-432.

9. Chen W, Ma Y, Ye H, He Y, Li X, Li J, et al. ERK1/2 is involved in cyclic compressive force-induced IL-6 secretion in MLO-Y4 cells. Biochem Biophys Res Commun. 2010;401(3):339-343.

10. Hotamisligil GS, Davis RJ. Cell Signaling and Stress Responses. Cold Spring Harb Perspect Biol. 2016;8(10).

11. Tassinary JA, Lunardelli A, Basso BS, Stulp S, Pozzobon A, Pedrazza L, et al. Therapeutic ultrasound stimulates MC3T3-E1 cell proliferation through the activation of NF-kappaB1, p38alpha, and mTOR. Lasers Surg Med. 2015;47(9):765-772.

12. Sinfield JK, Das A, O'Regan DJ, Ball SG, Porter KE, Turner NA. p38 MAPK alpha mediates cytokine-induced IL-6 and MMP-3 expression in human cardiac fibroblasts. Biochem Biophys Res Commun. 2013;430(1):419-424.

13. Nakatsu Y, Matsunaga Y, Yamamotoya T, Ueda K, Inoue Y, Mori K, et al. Physiological and Pathogenic Roles of Prolyl Isomerase Pin1 in Metabolic Regulations via Multiple Signal Transduction Pathway Modulations. Int J Mol Sci. 2016;17(9). 
14. Jimi E, Fukushima H. [NF-kappaB signaling pathways and the future perspectives of bone disease therapy using selective inhibitors of NF-kappaB]. Clin Calcium. 2016;26(2):298-304.

15. Vriend J, Reiter RJ. Melatonin, bone regulation and the ubiquitin-proteasome connection: A review. Life Sci. 2016;145:152-160.

16. Jimi E. The Role of BMP Signaling and NF-kappaB Signaling on Osteoblastic Differentiation, Cancer Development, and Vascular Diseases--Is the Activation of NFkappaB a Friend or Foe of BMP Function? Vitam Horm. 2015;99:145-170.

17. Wu D, Xie J, Wang X, Zou B, Yu Y, Jing T, et al. Micro-concentration Lipopolysaccharide as a Novel Stimulator of Megakaryocytopoiesis that Synergizes with IL-6 for Platelet Production. Sci Rep. 2015;5:13748.

18. Wang X, Zhu Y, Zheng S, Ni C, Zhao L, Liu C, et al. Amiloride inhibits osteoclastogenesis by suppressing nuclear factor-kappaB and mitogen-activated protein kinase activity in receptor activator of nuclear factor-kappaB-induced RAW264.7 cells. Mol Med Rep. 2015;11(5):3451-3456.

19. Kang JH, Ting Z, Moon MR, Sim JS, Lee JM, Doh KE, et al. 5-Lipoxygenase inhibitors suppress RANKL-induced osteoclast formation via NFATc1 expression. Bioorg Med Chem. 2015;23(21):7069-7078.

20. Zhao ZH, Luo SJ, Li J, Tang H, Li ZH, Chen GP, et al. A new four-point bending system to supply cultured adhensive cells in vitro with cyclic uniaxial strain. Key Engineering Materials. 2007;330:1133-1136.

21. Li L, Yang Z, Zhang H, Chen W, Chen M, Zhu Z. Low-intensity pulsed ultrasound regulates proliferation and differentiation of osteoblasts through osteocytes. Biochem Biophys Res Commun. 2012;418(2):296-300.

22. Wu JY, Chen CH, Yeh LY, Yeh ML, Ting CC, Wang YH. Low-power laser irradiation promotes the proliferation and osteogenic differentiation of human periodontal ligament cells via cyclic adenosine monophosphate. Int J Oral Sci. 2013;5(2):85-91.

23. Bakker AD, Kulkarni RN, Klein-Nulend J, Lems WF. IL-6 alters osteocyte signaling toward osteoblasts but not osteoclasts. J Dent Res. 2014;93(4):394-399.

24. Urschel K, Cicha I, Daniel WG, Garlichs CD. Shear stress patterns affect the secreted chemokine profile in endothelial cells. Clin Hemorheol Microcirc. 2012;50(1-2):143-152.

25. Tripuwabhrut $P$, Mustafa K, Brudvik $P$, Mustafa $M$. Initial responses of osteoblasts derived from human alveolar bone to various compressive forces. Eur $J$ Oral Sci. 2012;120(4):311-318.

26. Kobayashi K, Tanaka M, Nebuya S, Kokubo K, Fukuoka Y, Harada Y, et al. Temporal change in IL-6 mRNA and protein expression produced by cyclic stretching of human pulmonary artery endothelial cells. Int J Mol Med. 2012;30(3):509-513.

27. Palmqvist P, Persson E, Conaway HH, Lerner UH. IL-6, leukemia inhibitory factor, and oncostatin $\mathrm{M}$ stimulate bone resorption and regulate the expression of receptor activator of NF- $\mathrm{BB}$ ligand, osteoprotegerin, and receptor activator of NF- $\mathrm{BB}$ in mouse calvariae. The Journal of Immunology. 2002;169(6):3353-3362.

28. Kuroyanagi G, Tokuda H, Yamamoto N, Matsushima-Nishiwaki R, Mizutani J, Kozawa O, et al. Resveratrol amplifies BMP-4-stimulated osteoprotegerin synthesis via p38 MAP kinase in osteoblasts. Mol Med Rep. 2015;12(3):3849-3854.

29. Wang T, Zhang X, Li JJ. The role of NF-kappaB in the regulation of cell stress responses. Int Immunopharmacol. 2002;2(11):1509-1520.

30. Madrid LV, Mayo MW, Reuther JY, Baldwin AS, Jr. Akt stimulates the transactivation potential of the RelA/p65 Subunit of NF-kappa B through utilization of the Ikappa B kinase and activation of the mitogen-activated protein kinase p38. J Biol Chem. 2001;276(22):18934-18940. 
31. Tomomura M, Suzuki R, Shirataki Y, Sakagami H, Tamura N, Tomomura A. Rhinacanthin $\mathrm{C}$ Inhibits Osteoclast Differentiation and Bone Resorption: Roles of TRAF6/TAK1/MAPKs/NF-kappaB/NFATc1 Signaling. PLoS One. 2015;10(6):e0130174.

32. Iolascon G, Resmini G, Tarantino U. Mechanobiology of bone. Aging Clin Exp Res. 2013;25 Suppl 1:S3-7.

33. Rubin CT, Lanyon LE. Regulation of bone mass by mechanical strain magnitude. Calcified tissue international. 1985;37(4):411-417.

34. $\mathrm{Xu} \mathrm{J}, \mathrm{Yu} \mathrm{B}$, Hong $\mathrm{C}$, Wang $\mathrm{CY}$. KDM6B epigenetically regulates odontogenic differentiation of dental mesenchymal stem cells. Int J Oral Sci. 2013;5(4):200-205.

35. Mackiewicz Z, Niklinska WE, Kowalewska J, Chyczewski L. Bone as a source of organism vitality and regeneration. Folia Histochem Cytobiol. 2011;49(4):558-569.

36. Henkel J, Woodruff MA, Epari DR, Steck R, Glatt V, Dickinson IC, et al. Bone Regeneration Based on Tissue Engineering Conceptions-A 21st Century Perspective. Bone Research. 2013(3):216-248. 